\title{
COMPORTAMENTO GEOQUÍMICO DOS ELEMENTOS TERRAS RARAS DA SEQUÊNCIA METACARBONÁTICA MAGNESIANA PRÉ-CAMBRIANA ( 1.8Ga) DA FAIXA MÓVEL ORÓS
}

\author{
CLÓVIS VAZ PARENTE*, JEAN JACQUES GUILLOU ** \& LUIZ EDIVAN CARVALHO JÚNIOR***
}

\begin{abstract}
GEOCHEMICAL BEHAVIOR OF THE RARE EARTH ELEMENTS OF THE PRE-CAMBRIAN MAGNESIAN METACARBONATE SEOUENCE ( 1.8Ga) OF THE OROS MOBILE BELT Geochemical studies of the Rare Earth Elements (REE) in magnesian carbonate sequences are still rare, mainly in Brazil. The reasons for this are numerous and vary from the low content of these elements in this kind of rocks to the lack of knowledge about the their distribution in carbonate rocks. The increase of sensibility of the analytical methods (ICP) made it possible to detect extremely low values and with better knowledge of these elements in sedimentary environments, its use has been a valuable tool to the understanding of magnesian carbonate deposits. The study of these elements in the magnesian metacarbonatic sequence of the Precambrian Orós Mobile Belt $(\sim 1.8 \mathrm{Ga})$, which is characterized by an association of carbonates that vary from calcitic marbles (open sea) to dolomitic and magnesitic marbles (paralic marine) showed that there is a fractionation of the LREE from the calcitic marbles to the dolomitic and to the magnesitic marbles. In calcitic marbles, the REE are associated with the clay fraction, while in magnesitic marbles they seem to be associated with organic complexes and/or soluble complexes. The magnesitic marbles also present positive Ce and negative Eu anomalies, probably as a result of a shallow marine shelf environment under the influence of a continental reduced environment (lagunar). The magnesitic marbles also show a positive anomaly of $\mathrm{Ce}$ and Eu relative to the modern seawater, suggesting that the Proterozoic seawater was richer in these elements than its modern equivalent. seawater.

Keywords: Magnesite, Geochemical, Earth Rare Element, Oros Mobile Belt

RESUMO $O$ estudo geoquímico, através dos Elementos Terras Raras (ETR) em sequências carbonáticas magnesianas, é ainda raro, sobretudo no Brasil. As razões são várias e envolvem desde o baixo teor desses elementos juntos a essas rochas, outrora, aquém do limite de detecção dos equipamentos analíticos até a falta de conhecimentos sobre a distribuição desses elementos ao seio das rochas carbonáticas. Todavia, com a evolução da instrumentação analítica (ICP), capaz de detectar valores extremamente baixos e com o melhor conhecimento sobre a distribuição desses elementos em ambientes sedimentares, a sua utilização tem sido uma ferramenta indispensável à compreensão de sequência de rochas carbonáticas magnesianas. $\mathrm{O}$ conhecimento desses elementos, na sequência metacarbonática magnesiana pré-cambriana da Faixa Móvel Orós ( $1,8 \mathrm{Ga})$, que é caracterizada por uma assembleia de rochas metacarbonáticas, que vai de mármores calcíticos (mar aberto) a mármores dolomíticos e magnesíticos (ambientes marinhos parálicos), revelou que há um fracionamento de elementos terras leves (ETRL), indo dos mármores calcíticos, através dos mármores dolomíticos, aos mármores magnesíticos. Nos mármores calcíticos, os ETR estão em associações com as frações argilosas, enquanto nos mármores magnesíticos parecem ocorrer associados aos complexos orgânicos e/ou complexos solúveis. Os mármores magnesíticos apresentam ainda uma anomalia positiva de $\mathrm{Ce}$ e negativa de Eu. Isso pode indicar um ambiente plataformal marinho raso com influência redutora e continental (lagunar). Os mármores magnesíticos mostram também uma anomalia positiva de Ce e Eu em relação à água do mar atual, sugerindo diferenças composicionais, materializadas, sobretudo, por um maior enriquecimento desses elementos nas águas dos mares primitivos.
\end{abstract}

Palavras-chave: Magnesita, Geoquímica, Terras-Raras, Faixa Móvel Orós

INTRODUÇÃO O estudo geoquímico, enfocando os elementos terras raras (ETR) em rochas magnesíticas, é ainda raro, limitando-se, ao conhecimento dos autores, aos trabalhos de Morteani et al. (1982, 1983), Qiusheng, (1988), Tufar et al. (1989) e Moller (1989).

Segundo Morteani et al. (1982, 1983), é possível separar, através dos ETR, os mármores magnesíticos de origem sedimentar e metassomática. Para estes autores, os magnesititos metassomáticos, em geral espáticos, apresentam padrões de ETR subparalelos aos dolomitos encaixantes, em que se verifica o mesmo comportamento dos terras raras, inclusive as mesmas anomalias negativas de $\mathrm{Ce}$ e Eu. Entretanto, os autores assinalam que os dolomitos são ligeiramente mais ricos em terras raras leves (ETRL) que os magnesititos.

Quisheng (1988), ao estudar o maior depósito de magnesita estratiforme do mundo, o de Liaodong (China), de idade paleoproterozóica, verificou que o padrão de ETR dos mármores magnesíticos e dolomíticos normalizados pelos condritos, era similar àqueles das rochas sedimentares, particularmente aqueles das rochas carbonáticas de Ronov et al. (1974). Ele observou também que o valor total dos ETR dos magnesititos era relativamente maior que aqueles das rochas carbonáticas de Ronov et al.(1974). Quisheng (1988) verificou ainda que ambos (mármores magnesíticos e dolomíticos encaixantes) tinham uma anomalia negativa de $\mathrm{Eu}\left(\mathrm{Eu}: \mathrm{Eu}^{*}=0,66-0,97\right.$ e 0,56-0,74 respectivamente). Em relação ao Ce, este autor observou uma anomalia positiva nessas rochas.

Tufar et al. (1989), utilizando os ETR como parte complementar ao estudo do depósito de magnesita espática de Radenhein (Áustria), de idade neo-paleozóica, verificaram que as amostras de magnesitas apresentavam anomalia positiva de Eu e nenhuma anomalia de Ce.

Moller (1989) verificou que a quantidade e o fracionamento dos ETR em rochas magnesíticas estão associados a três fatores: 1. à composição dos fluidos formadores dos minerais; 2 . à composição química dos prcursores da magnesita ou os minerais fontes do íon de $\mathrm{Mg}+$, que hospedaram os lantanídeos; 3. ao modo de cristalização do carbonato (primário ou secundário). De acordo com Moller (1989), na formação de magnesita de origem sedimentar, o fracionamento está diretamente associado ao tamanho iônico dos ETR trivalentes (1.13-
$0.94 \AA ̊)$, que é aproximadamente similar ao do $\mathrm{Ca}^{2+}$ (1. $14 \AA \AA$ ) e superior ao do $\mathrm{Mg}(0.86 \AA)$

Assim, é possível detectar os ETR em calcita e dolomita, embora, não o seja em anidrita. $\mathrm{O}$ mesmo ocorre com a magnesita, que quando inicia a sua formação, os fluidos já são efetivamente empobrecidos nos lantanídeos. Entretanto, para Möller (1989), a magnesita pode apresentar valores perfeitamente detectáveis de ETR, devido as inclusões de pequenas frações de minerais terrígenos argilosos. Este efeito dos ETR é observado em sequência carbonática e em sequências anidríticas de depósitos de sal.

O presente trabalho constitui o primeiro estudo geoquímico envolvendo os ETR, em sequências metacarbonáticas magnesianas, realizado no Brasil. Tem como objetivo mostrar o padrão de distribuição desses elementos junto à mármores calcíticos, dolomíticos e magnesíticos que afloram no domínio da Faixa Móvel Orós, de idade mesoproterozóica $(\sim 1.8 \mathrm{Ga})$, entre Alencar $(\mathrm{Ce})$ e Pio IX $(\mathrm{Pi})$, de modo a compreender a evolução e diferenciação dessa sequência metacarbonática.

GEOLOGIA DOS DEPÓSITOS DE MAGNESITA Os depósitos principais e algumas ocorrências de magnesita do Ceará formam um rosário de lentículas que se integram dentro de um conjunto metacarbonático descontínuo, que se prolonga por mais de $140 \mathrm{~km}$, entre Pio IX, (PI), a oeste, e Orós, (CE) a leste (Fig. 1). Todas essas rochas metacarbonáticas são intercaladas em uma sequência metavulcano-sedimentar de fácies xisto verde à anfibolito, recortada por granitos do Mesoproterozóico e Neoproterozóico e por corpos básico-ultrabásicos do Neoproterozóico. Datações geocronológicas (método $\mathrm{U} / \mathrm{Pb}$ ) sobre alouns metariólitos intercalados nas rochas metassedimentares têm revelado idades em torno de 1800 Ma (Sá 1991, Van Schumus et al. 1995), correspondendo provavelmente a idade da sedimentação. As rochas metassedimentares são sobretudo metapelíticos, formados em particular por xistos aluminosos que apresentam em seu seio intercalações de quartzitos, mármores calcíticos, dolomíticos e magnesíticos, rochas cálcio-silicáticas e quartzitos carbonosos. Estes últimos indicam um ambiente confinado rico em matéria orgânica, o que

* Departamento de Geologia - Universidade Federal do Ceará-Bloco 912. Campus do PICI- CEP, Email: clovis@ufc.br 


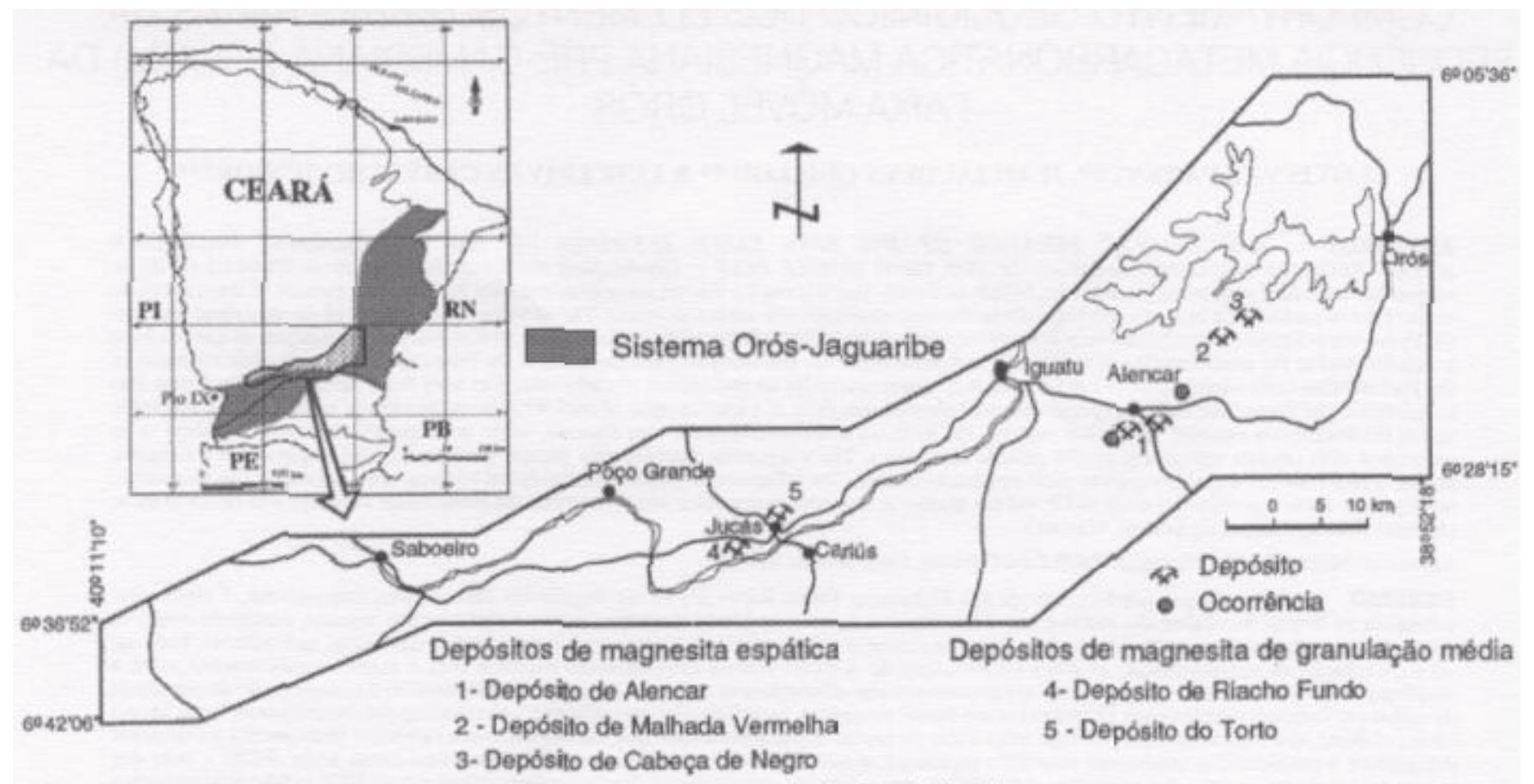

Figura l- Mapa de localização dos depósitos e ocorrências de magnesita do Ceará, Brasil.

era pouco comun para a época. Esse conjunto litológico apresenta uma direcão principal NE-SW na parte centro-oeste, N-S na parte centra da faixa e NE-SW no extremo norte da Faixa. Para maiores detalhes sobre a estratigrafia desta região consultar Parente (1995) e Parente \& Arthaud(1995).

GEOQUÍMICA DOS ELEMENTOS TERRAS RARAS Apresentação dos Resultados As amostras estudadas, no total de 22, foram analisadas no Laboratório GEOLAB da GEOSOL. Os ETR foram determinados por ICP 3500 da ARL com retículo de 1200 ranhuras por $\mathrm{mm}$, montagem Czem-Turner, $1 \mathrm{~m}$ de distância focal, varredura de 1890 a $8000 \mathrm{~A}^{\circ}$, dispersão linear de $8 \mathrm{~A}^{\circ} / \mathrm{mm}$, gerador de alta frequência de $27 \mathrm{MHZ}$ e potência de $1200 \mathrm{~W}$, tocha de plasma de quartzo, fluxo de argônio de 121/min, envolvendo pré-concentração em resina de troca iồnica. Para a realização dessas análises, as amostras são solubilizadas por ataque triácido: $\mathrm{HF}-\mathrm{HC10}_{4}-\mathrm{HCl}$ em cadinho de teflon, levadas a seco para eliminar o flúor e retomadas com solução clorítica. Resíduos não atacados são separados e fundidos com metaborato de lítio, o vidro solubilizado em $\mathrm{HG}$ e adicionado à solução inicial, que é levada a seco e retomada com solução clorídica. No processo usado no GEOLAB, a pré-concentração é feita usando resina catiônica equilibrada com $\mathrm{HCl}$. Os padrões são sintetizados a partir de óxidos espectroscopicamente puros da Johnson Mattey, solubilizados por solução clorídrica. Dessas amostras, 05 representam mármores calcíticos localizados na zona oeste da área, entre Cruzeta (CE) e Pio IX (PI), 09 amostras correspondem a mármores dolomíticos encaixantes dos mármores magnesíticos espáticos, localizados na porção centro-leste, junto aos depósitos de Malhada Vermelha e Cabeça de Negro e 08 são mármores magnesíticos espáticos do Depósito de Cabeça de Negro. Das amostras correspondentes aos mármores dolomíticos, 03 são mármores dolomíticos brechifiçados, cimentados por calcita espática. A tabela 1 apresenta esses resultados.

DISCUSSÃO Os mármores calcíticos apresentam a ZETR variando de 6,4 a 23,47ppm, os mármores dolomíticos calcíticos indo de 30,2 a $112,4 \mathrm{ppm}$, os mármores dolomíticos variando entre 11,3 a 20,6ppm e os mármores magnesíticos espáticos apresentando valores entre 5,3 a 11,5ppm. A razão $\mathrm{La}_{n} / \mathrm{Lu}_{n}$ diminui dos mármores calcíticos (21,0-61,03), aos mármores magnesíticos $(3,9-19,6)$, com os mármores dolomíticos calcíticos $(4,6-28,6)$ e os mármores dolomíticos $(10,01$ a 21,50$)$ apresentando valores intermediários entre esses dois tipos litológicos, indicando um fracionamento dos ETRL entre essas rochas.

O padrão dessas rochas, normalizado a folhelhos de NASC de Haskin et al. 1968, mostra um maior enriquecimento em ETR junto aos mármores dolomíticos calcíticos brechificados, uma diminuição progressiva dos ETRL indo dos mármores calcíticos, através dos dolomíticos, aos magnesíticos, e um ligeiro enriquecimento em ETRP junto aos mármores magnesíticos espáticos (Fig. 2).

Por outro lado, ao comparar esses resultados com o padrão normalizado ao condrito de Evensen et al (1978), verifica-se que os mármores dolomíticos brechificados continuam sendo os termos mais enriquecidos em ETRL e que há um empobrecimento dos ETRL indo dos mármores calcíticos, através dos mármores dolomíticos comuns aos mármores magnesíticos (Fig. 3). Observa-se também uma anomalia negativa de Eu (a razão Eu/Eu* varia de 0,4 a 0,9 nos mármores calcíticos, de 0,6 a 0,7 nos mármores dolomíticos calcíticos, de 0,5 a 0,9 nos mármores dolomíticos comuns e de 0,5 a 0,7 nos magnesíticos), enquanto o Ce apresenta-se com uma anomalia ligeiramente positiva.

Ao comparar esses resultados com o padrão da água do mar, verifica-se que toda a sequência metacarbonática apresenta uma forte anomalia positiva do Ce e uma ligeira anomalia positiva do Eu (Fig.

4). Para uma melhor compreensão da distribuição dos ETR junto a esta sequência metacarbonática, utilizou-se ainda vários diagramas de variação que mostram a relação $\mathrm{Al}_{2} \mathrm{O}_{3}$ vs ETR (Fig.5) e ETR vs $\mathrm{MgO}$ (Fig.6).

Na tabela 2, verifica-se a matriz de correlação dos ETR nos mármores calcíticos do setor oeste da Faixa Orós. Neste caso, os ETR, particularmente $\mathrm{La}, \mathrm{Nd}, \mathrm{Ce}, \mathrm{Lu}, \mathrm{Yb}, \mathrm{Er}, \mathrm{Ho}, \mathrm{Dy}, \mathrm{Gd}$, Eu e Sm mostram uma significante correlação negativa com o $\mathrm{CaO}$ (fator de correlação $r$ variando de $-0,75$ a $-0,95$ ) e positiva com o $\mathrm{MgO}$ (r variando de 0,72 a 0,92 ) e com o $\mathrm{Al}_{2} \mathrm{O}_{3}$ (r variando de 0,81 a 0,98 ) (ver também figura

5). Como o $\mathrm{Al}_{2} \mathrm{O}_{3}$ varia positivamente com $\mathrm{SiO}_{2}$ e $\mathrm{MgO}$ e, em menor significância, com $\mathrm{Fe}_{2} \mathrm{O}_{3}$, indicando que o mineral silicático aluminoso associado aos mármores calcíticos é uma clorita magnesiana com $\mathrm{Fe}$, pode-se pensar que os ETR podem estar mais associados aos minerais argilosos que junto a calcita do mármore calcítico.

A tabela 3 contém a matriz de correlação dos ETR junto aos mármores dolomíticos. Neste caso, não se verifica nenhuma correlacão significante entre os ETR com os elementos maiores como $\mathrm{CaO}$ e $\mathrm{MgO}$. Entretanto, esses ETR mostram uma ligeira correlação positiva com o $\mathrm{Al}_{2} \mathrm{O}_{3}$ e o $\mathrm{Fe}_{2} \mathrm{O}_{3}$. La e Ce mostram também uma ligeira correlação positiva com $\mathrm{MnO}$, o que sugere uma afinidade com óxidohidróxido de ferro-manganês. A tabela 4 contem a matriz de correlação dos ETR junto aos mármores magnesíticos espáticos do depósito de Cabeça de Negro e Malhada Vermelha. Da mesma forma que nos mármores calcíticos, os ETR mostram uma corrrelacão negativa, embora de menor significância ( $\boldsymbol{r}$ variando de $-0,46 \mathrm{a}-0,81)$ com o $\mathrm{CaO}$, uma correlação positiva com o $\mathrm{MgO}$, também de menor qualidade 

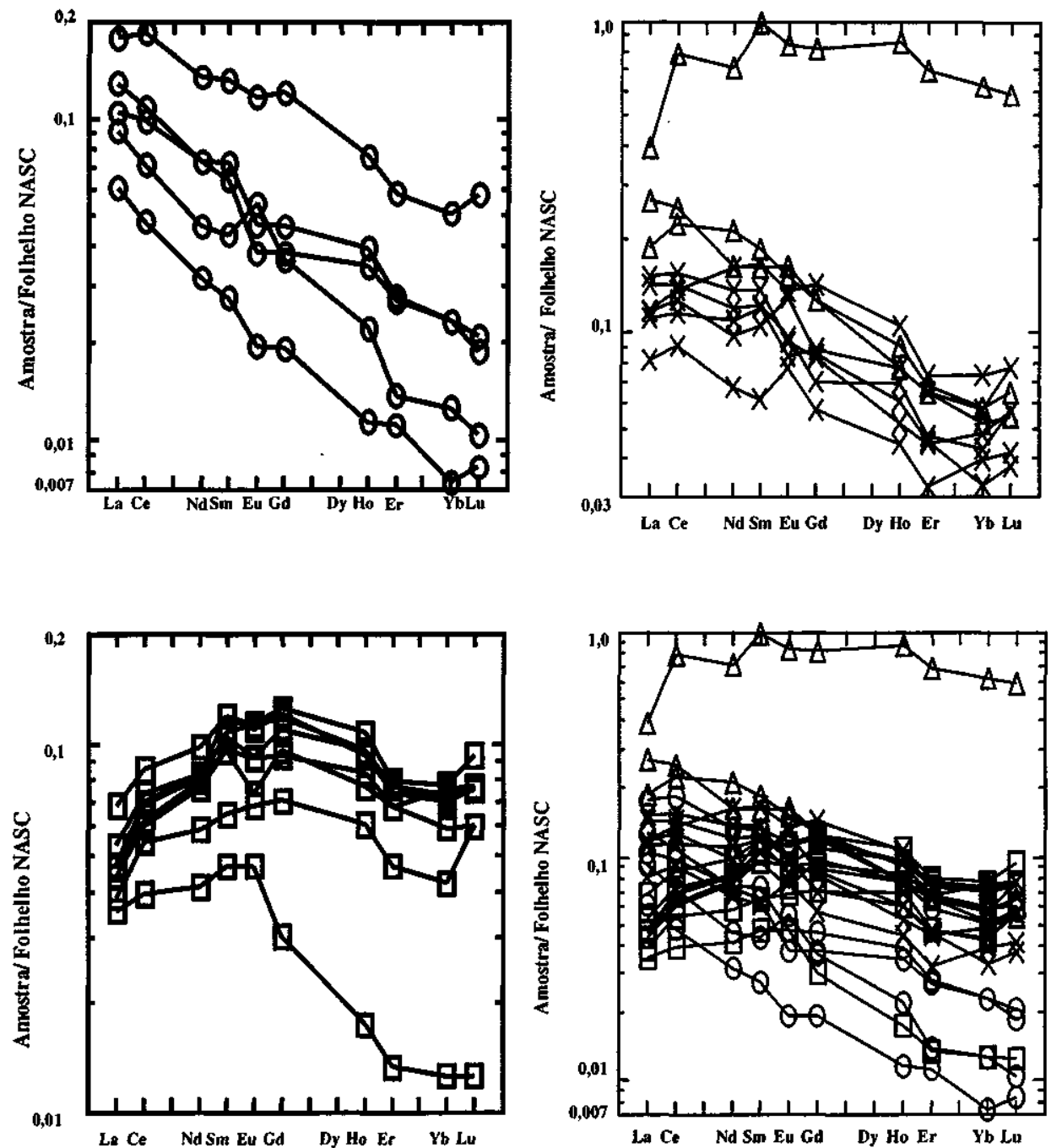

Figura 2 - Padrão dos mármores normalizados ao NASC de Haskin et al. (1968). (a) - mármores calcíticos. (b) -mármores dolomíticos; a curva com triângulos representa os mármores dolomíticos calcíticos brechados e a com cruz os mármores dolomíticos comuns, (c) - mármores magnesíticos espáticos. (d) - rochas metacarbonáticas estudadas, onde as curvas com círculos representam os mármores calcíticos, as do triângulo os mármores dolomíticos calcíticos brechados, as da cruz os mármores dolomíticos e as do quadrado os mármores magnesíticos

(r-variando de 0,5 a 0,75 ) e praticamente nenhuma correlação de qualidade com o $\mathrm{Al}_{2} \mathrm{O}_{3}(\mathrm{r}<4)$ (ver figura $5 \mathrm{c}$ ). Os ETR também mostram um certa correlação negativa com o $\mathrm{MnO}$ ( $r$ variando entre $-0,63$ a -0,82), e nenhuma com o $\mathrm{Fe}_{2} \mathrm{O}_{3}$ ( $\mathrm{r}$ situando-se entre -0,16 e $-0,42$ ).

Por outro lado, a nível de sequência metacarbonática, praticamente não se tem nenhuma correlação de significância entre os ETR e os demais elementos (ver figura $5 \mathrm{~d}$ e $6 \mathrm{c}$ ), pois todos os elementos possivelmente correlacionáveis, apresentam um índice de correlação muito baixo ( $r$ inferior ou igual a $+0,5$ ou a $-0,5$ ).

Considerando que os ETR se distribuem particularmente na fração argilosa das rochas carbonáticas, pode-se pensar que esta pequena diferença em favor dos mármores calcíticos possa estar ligada ao seu caráter menos fracionado que aquele dos mármores dolomíticos e magnesíticos. Isso justificaria portanto, o comportamento ligeiramente diferente dos ETR entre os mármores calcíticos, dolomíticos e os magnesíticos.

No detalhe, há uma diminuição dos ETRL dos mármores calcíticos em direção às rochas magnesíticas (Fig.6a ) enquanto os ETRP permanecem quase constantes (Fig.6b). Todavia, no geral, nota-se uma diminuição do ZETR em direção aos termos mais magnesianos (Fig.6c). Considerando que os minerais argilosos parecem não influenciar o comportamento dos ETR junto aos mármores magnesíticos, é provável que a distribuição desses elementos junto a estas rochas possa estar associada à tendência desses elementos formar complexos solúveis e/ou complexos orgânicos em ambientes de alcalinidade neutra ou elevada.
ANOMALIAS de Ce e Eu O comportamento desses dois elementos tem sido de grande utilidade na reconstituição paleoambiental. A anomalia negativa de $\mathrm{Ce}$ em rochas sedimentares, particularmente em rochas carbonáticas, tem sido utilizada comumente como um argumento de origem marinha, enquanto a sua inexistência é atribuída a influência de águas continentais (Tlig 1987). Entretanto, águas marinhas não empobrecidas em Ce tem sido também encontradas. Nesse sentido, Martim et al. (1976 in Fleet 1984) ao estudarem o Estuário Gironda verificaram que a razão $\mathrm{Ce} / \mathrm{La}$ permanece constante, indicando que o Ce não é removido em solução em ambientes estuarinos. Amostras de água do Mar Barent analisadas por Hogdahl et al. (1968 in Fleet 1984), também não exibem anomalias de Ce e a água próxima à costa Leste dos EUA é 10 a 100 vezes mais rica em Ce que a amostra do oceano Atlântico adjacente. Cherts depositados em mar profundo tem também anomalias negativa em Ce, porém aqueles formados em extensas plataformas parecem não mostrá-la (Fleet 1984).

Para Fleet (1984), a ausência de um empobrecimento em Ce nos sedimentos marinhos próximo à costa (nearshore e coastal) pode estar associada a dois fatores distintos: 1- as águas continentais não são deplecionadas em $\mathrm{Ce}$ e este elemento provavelmente não se comporta de maneira diferente dos outros ETR no meio continental. Assim, em áreas próximas ao continente, em regiões plataformais, a mistura entre águas continentais não empobrecidas em Ce e águas oceânicas empobrecidas em Ce causa uma deficiência em Ce mais ou menos pronunciada, que pode ter sido herdada dos minerais autigênicos desenvolvi- 
Tabela l- Concentração dos Elementos Terras Raras (em ppm) das rochas metacarbonáticas da Faixa Móvel Orós

\begin{tabular}{|c|c|c|c|c|c|c|c|c|c|c|c|c|c|c|c|}
\hline & Amostra & $\mathrm{La}$ & $\mathrm{Ce}$ & Nd & $S m$ & Eu & Gd & Dy & Ho & Er & $\mathrm{Yb}$ & Lu & Total & Lallun & $\overline{E u} /$ Eun \\
\hline \multirow{2}{*}{$\begin{array}{l}\text { Mármore } \\
\text { calcítico } \\
\text { "+1 }\end{array}$} & CMDIM & 4.098 & 7.887 & 2364 & 0.370 & 0.047 & 0.198 & 0.169 & 0.036 & 0.092 & 0.072 & 0.009 & 14.349 & 47.265 & 0.481 \\
\hline & CMDIN & 1.947 & 3.486 & 1.017 & 0.157 & 0.024 & 0.100 & 0.057 & 0.012 & 0.038 & 0.023 & 0.004 & 6.450 & 50.526 & 0.548 \\
\hline$n+4$ & CMDIP & 2.940 & 5.239 & 1,480 & 0.249 & 0.068 & 0.190 & 0.128 & 0.023 & 0.047 & 0.039 & 0.005 & 9.659 & 61.036 & 0.920 \\
\hline${ }^{n+}$ & CMDSA & 5.683 & 13.480 & 4.310 & 0.750 & 0.145 & 0.626 & 0.407 & 0.080 & 0.200 & 0.157 & 0.028 & 23.473 & 21.068 & 0.630 \\
\hline$m$ & CMDSB & 3.344 & 7.154 & 2.373 & 0.417 & 0.058 & 0.239 & $0.19 !$ & 0.041 & 0.095 & 0.072 & 0.010 & 12.871 & 34.711 & 0.516 \\
\hline \multirow{2}{*}{$\begin{array}{l}\text { Már. } \\
\text { dolomítico } \\
\text { calcítico } \\
\text { H+1 }\end{array}$} & CMD6A & 12.560 & 57.450 & 22.710 & 5.637 & 1.042 & 4.248 & 4.557 & 0.899 & 2.352 & 1.920 & 0.280 & 112.476 & 4.656 & 0.626 \\
\hline & CMD6B & 8.548 & 18.560 & 5.223 & 0.918 & 0.202 & 0.660 & 0.483 & 0.095 & 0.230 & 0.180 & 0,031 & 32.331 & 28.623 & 0.758 \\
\hline 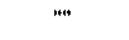 & CMD6F & 5.984 & 16.420 & 6.810 & 1.060 & 0.188 & $0.66 \mathrm{I}$ & 0.458 & 0.080 & 0.220 & 0.160 & 0.026 & 30.274 & 23.890 & 0.640 \\
\hline \multirow{2}{*}{$\begin{array}{l}\text { Mármore } \\
\text { dolomítico }\end{array}$} & CMD6C & 4.886 & 11.340 & 4.400 & 0.780 & 0.116 & 0.434 & 0.302 & 0.054 & 0.151 & 0.148 & 0.027 & 20.626 & 18.784 & 0.556 \\
\hline & CMD6D & 4.573 & 10.470 & 3.850 & 0.700 & 0.120 & 0.363 & 0.320 & 0.072 & 0.160 & 0.133 & 0.027 & 18.893 & 17.581 & 0.654 \\
\hline+14 & CMD7F & 3.729 & 9.348 & 3.138 & 0.600 & 0.159 & 0.444 & 0.310 & 0.063 & 0.155 & 0.102 & 0.018 & 16.215 & 21.504 & 0.903 \\
\hline "'"' & CMD8I & 3.773 & 10.050 & 5.180 & 0.940 & 0.169 & 0.746 & 0.508 & 0.110 & 0.250 & 0.228 & 0.037 & 19.003 & 10.585 & 0.597 \\
\hline ייי & CMD8J & 2.617 & 6.615 & 2.155 & 0.350 & 0.096 & 0.295 & 0.231 & 0.046 & 0.110 & 0.123 & 0.020 & 11.387 & 13.583 & 0.890 \\
\hline $4+4$ & CMDSL & 3.568 & 8.362 & 3.510 & 0.680 & 0.105 & 0.463 & 0.360 & 0.080 & 0.220 & 0.176 & 0.037 & 15.440 & 10.010 & 0.542 \\
\hline \multirow{2}{*}{$\begin{array}{l}\text { Mármore } \\
\text { magnesítico } \\
\text {,.". }\end{array}$} & CMDTC & 2.188 & 6.238 & 3.137 & 0.680 & 0.136 & 0.625 & 0.530 & 0.097 & 0.250 & 0.216 & 0.036 & 11.563 & 6.309 & 0.627 \\
\hline & CMD7D & 1.405 & 4.389 & 2.442 & 0.550 & 0.113 & 0.484 & 0.410 & 0.087 & 0.230 & 0.184 & 0.029 & 8.236 & 5.029 & 0.656 \\
\hline "'t" & CMD7E & 1.133 & 2.872 & 1.322 & 0.268 & 0.058 & 0.158 & 0.100 & 0.018 & 0.045 & 0.039 & 0.006 & 5.327 & 19.601 & 0.795 \\
\hline 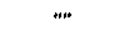 & CMD\&A & 1.234 & 3.967 & 1.874 & 0.370 & 0.085 & 0.366 & 0.240 & 0.063 & 0.160 & 0.131 & 0.029 & 7.075 & 4.417 & 0.699 \\
\hline$m$ & CMD8B & 1.718 & 5.386 & 2.644 & 0.680 & 0.140 & 0,645 & 0.530 & 0.112 & 0.270 & 0,240 & 0.045 & 9.748 & 3.963 & 0.637 \\
\hline$" *$ & $\mathrm{CMD} 8 \mathrm{C}$ & 1.481 & 4.554 & $2.53 \mathrm{~J}$ & 0.610 & 0.141 & 0.613 & 0.630 & 0.100 & 0.261 & 0.227 & 0.037 & 8.566 & 4,155 & 0.698 \\
\hline$n+$ & CMD8D & 1.485 & 5.017 & 2.602 & 0.550 & 0.091 & 0.503 & 0.410 & 0.080 & 0.230 & 0.234 & 0.037 & 9.104 & 4.166 & 0.520 \\
\hline$"$ & CMD8H & 1.512 & 5.107 & 2.660 & 0.600 & 0.114 & 0.571 & 0.470 & 0.100 & 0.261 & 0.220 & 0.037 & 9.279 & 4.242 & 0.587 \\
\hline
\end{tabular}
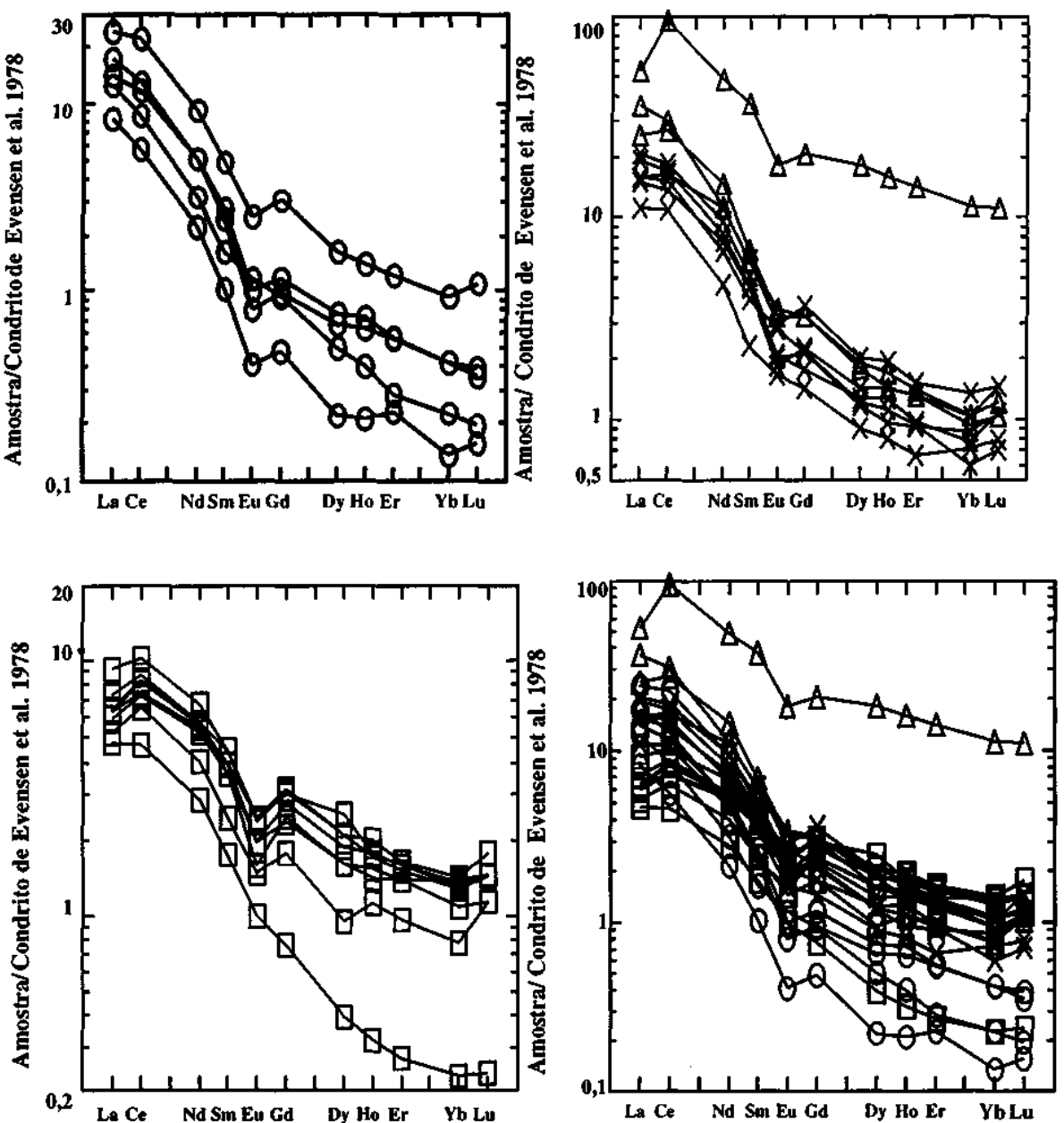

Figura 3 - (a) Padrão dos mármores calcíticos normalizados ao condrito de Evensen et al. (1978). (b)-Padrão dos mármores dolomíticos. (c) -Padrão dos mármores magnesíticos espáticos. (d) - Padrão das rochas metacarbonáticas estudadas. Os símbolos são os mesmos da figura $2 d$. 

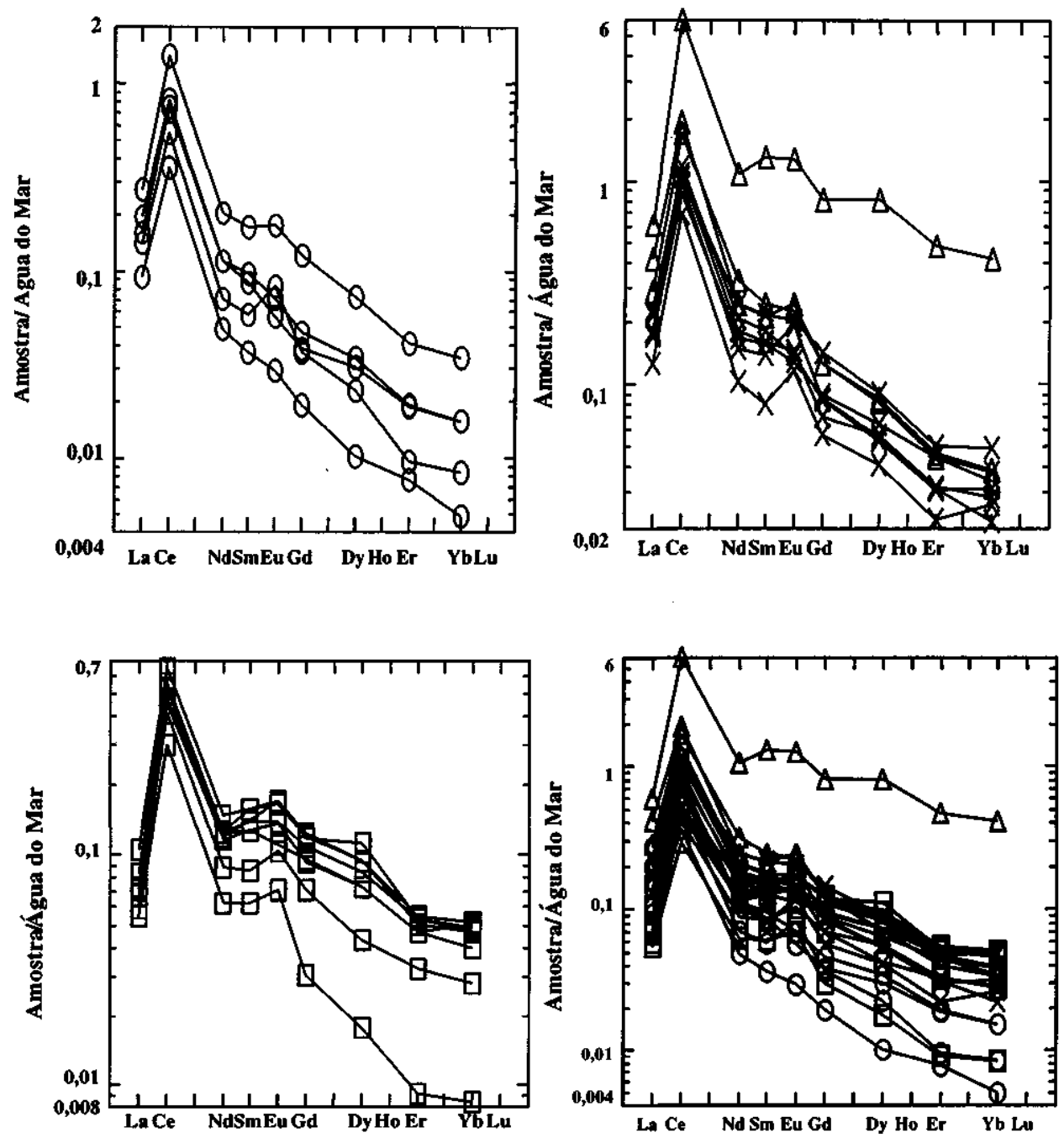

Figura 4-(a) - Padrão dos mármores calcíticos normalizados em relação à água do mar. (b) - Padrão dos mármores dolomíticos. (c) - Padrão dos mármores magnesíticos (d) -Padrão das rochas metacarbonáticas estudadas. Símbolos em (a) e (b) como na figura $2 b$ e em (c) e (d) como na figura $2 d$.

dos próximo à costa; 2- Em áreas de mares rasos, bacias marginais a epicontinentais, o Ce é aparentemente envolvido em partículas sólidas suspensas com os ETR remanescentes, e assim, apesar de tetravalentes, o Ce comporta-se como os outros ETR. Já em áreas remotas dos continentes, este elemento é submetido à remoção seletiva dentro das partículas sólidas finamente granuladas $(<0,1 \mu \mathrm{m}$, flocos de $\mathrm{Fe}-\mathrm{Mn})$. Como consequência, o Ce é separado dos seus vizinhos ( $\mathrm{La}$ e $\mathrm{Nd}$ ) e, assim, uma anomalia positiva ou negativa do Ce pode ocorrer nos sedimentos. Isso conduziu Shimizu \& Maskada (1977 in Fleet 1984), a sugerirem que o Ce é deplecionado em águas de mar aberto, mas não nos mares superficiais. ParaHogdahl et al. (1968), há uma forte relação entre ETR e a massa de água.

Eterhidge et al. (1982), em um estudo sobre o comportamento dos ETR nos oceanos em diferentes profundidades, observaram que, na água do mar, à profundidades inferiores a $100 \mathrm{~m}$, os ETR apresentavam uma anomalia negativa de $\mathrm{Eu}$, sem anomalia de $\mathrm{Ce}$ e um nítido enriquecimento dos ETRP em relação aos ETRL. Já em profundidade superior, verificava-se o desenvolvimento de anomalias negativas de $\mathrm{CeeEu}$.

Assim, em concordância com Fleet (1984), parece que a água do mar não é necessariamente empobrecida em Ce e que a remoção deste elemento na água do mar ocorre mais provavelmente no oceano aberto em vez de águas plataformais ou estuarinas.

Deve ser assinalado também que a ausência de uma anomalia negativa de $\mathrm{Ce}$ em rochas carbonáticas não é devido a influência diagenética geral, nem a dolomitização, mas, provavelmente, à formação dessas rochas em ambientes com águas não deplecionadas em $\mathrm{Ce}$.
Todavia, alguns autores admitem que os sedimentos marinhos são deplecionados em $\mathrm{Ce}$ e consideram que a depleção de $\mathrm{Ce}$ em águas oceânicas modernas está associada à incorporacão preferencial de $\mathrm{Ce}^{4+}$ em minerais autigênicos como nódulos de Mn e fosforitos (ver por exemplo Piper 1974, McLennant et al. 1979).

Sabe-se também que o fracionamento do $\mathrm{Ce}$ em relação aos outros ETR está associado à sua remoção mais fácil na presença de oxigénio. Assim, nos oceanos, o $\mathrm{Ce}^{3+}$ é oxidado para $\mathrm{Ce}^{4+}$, que é insolúvel, precipitando como $\mathrm{CeO}_{2}$, resultando num empobrecimento desse elemento na água do mar, em relação aos outros ETR.

Quanto à anomalia positiva de Eu nos sedimentos marinhos ou na água do mar, esta tem sido atribuída a um influxo hidrotermal, cujo processo é acompanhado também por um enriquecimento em ETRL (ver, dentre outros Michard et al. 1983, Tlig 1987). Isso é bem característico dos sedimentos desenvolvidos no Arqueano, em que os mares primitivos recebiam uma forte contribuição de fluidos hidrotermais. Já a anomalia negativa de Eu é considerada característica de um ambiente redutor em que $0 \mathrm{Eu}^{3}+$ é reduzido para $\mathrm{Eu}^{2+}$, embora alguns autores tenham sugerido que metamorfismo ou metassomatismo possa causar uma redução do Eu (ver, por exemplo, Jarvis et al. 1975 in Fleet 1984).

Morteani et al. (1983), por sua vez, consideram que a anomalia negativa de Eu é encontrada em minerais que foram formados de soluções com baixo valor em Eh, enquanto a anomalia positiva de Eu é atribuída a minerais formados em fluidos com alta fugacidade de oxigénio interagidos na decomposição de feldspatos.

Möller (1989) considera que o comportamento similar em ETR e os mesmos tipos de anomalias negativas de Ce e Eu entre os magnesi- 
A

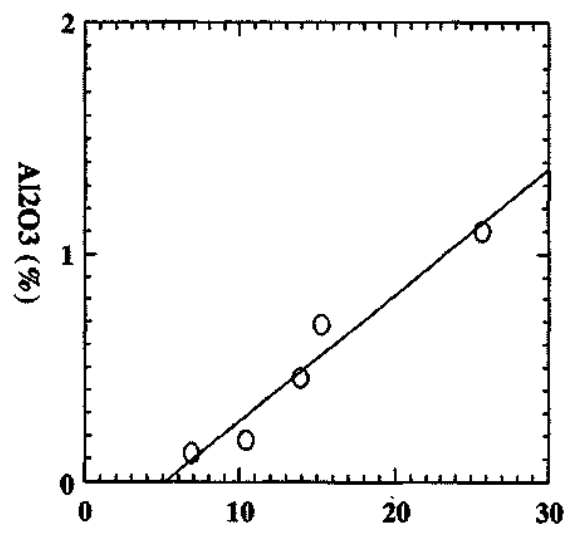

$\mathrm{La}+\mathrm{Ce}+\mathrm{Nd}+\mathrm{Sm}+\mathrm{Eu}+\mathrm{Gd}+\mathrm{Dy}+\mathrm{Ho}+\mathrm{Er}+\mathrm{L}$

C

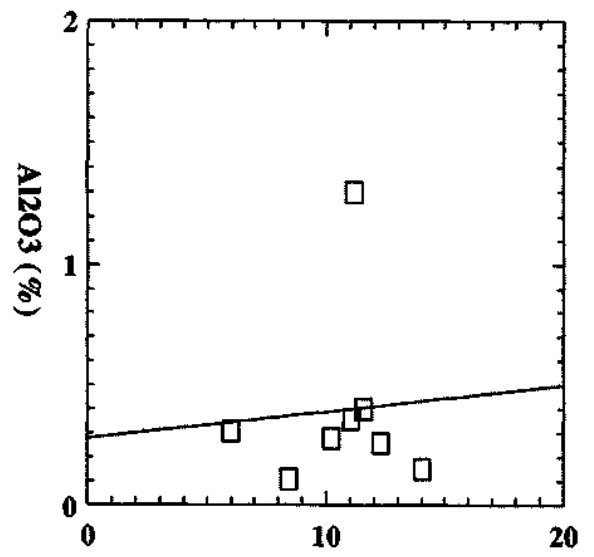

$\mathrm{La}+\mathrm{Ce}+\mathrm{Nd}+\mathrm{Sm}+\mathrm{Eu}+\mathrm{Gd}+\mathrm{Dy}+\mathrm{Er}+\mathrm{Yb}+\mathrm{Lu}$
B

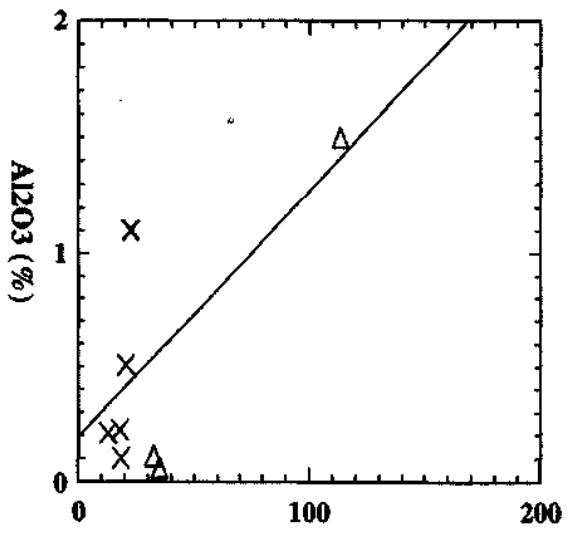

$\mathrm{La}+\mathrm{Ce}+\mathrm{Nd}+\mathrm{Sm}+\mathrm{Eu}+\mathrm{Gd}+\mathrm{Dy}+\mathrm{H}_{0}+\mathrm{Er}+\mathrm{Yb}+\mathrm{Lu}$

$\mathbf{D}$

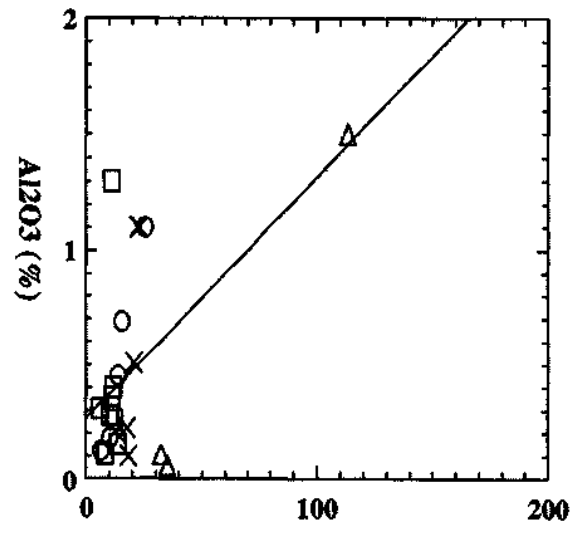

$\mathrm{La}+\mathrm{Ce}+\mathrm{Nd}+\mathrm{Sm}+\mathrm{Eu}+\mathrm{Gd}+\mathrm{Dy}+\mathrm{Ho}+\mathrm{Er}+\mathrm{Yb}+\mathrm{Lu}$

Figura 5 - Diagramas $\mathrm{Al}_{2} \mathrm{O}_{3}$ vs ETR. (a) - dos mármores calcíticos. (b) - dos mármores dolomíticos, onde o triângulo representa os mármores dolomíticos calcíticos brechados e a cruz os mármores dolomíticos. (c) - dos mármores magnesíticos. (d) - das rochas metacarbonáticas estudadas, onde o círculo representa os mármores calcíticos, o triângulo os dolomiticos calciticos, a cruz os dolomíticos e o quadrado os mármores magnesíticos.

Tabela 2-Matriz de correlação dos mármores calcíticos

\begin{tabular}{|c|c|c|c|c|c|c|c|c|c|}
\hline & $\mathrm{CaO}$ & $\mathrm{MgO}$ & $\mathrm{Al}_{2} \mathrm{O}_{2}$ & $\mathrm{Fe}_{2} \mathrm{O}_{2}$ & $\mathrm{FeO}$ & $\mathrm{P}_{2} \mathrm{O}_{5}$ & $\mathrm{SiO}_{2}$ & $\mathrm{MnO}$ & $\mathrm{TiO}_{2}$ \\
\hline Lu & $-0,88$ & 0,9 & 0,92 & $-0,04$ & 0,5 & 0,5 & 0,55 & $-0,36$ & 0,97 \\
\hline $\mathrm{Yb}$ & $-0,92$ & 0,91 & 0.96 & 0.08 & 0.45 & 0,53 & 0,64 & $-0,36$ & 0.91 \\
\hline Er & $-0,92$ & 0,92 & 0,96 & 0,08 & 0,41 & 0,54 & 0,62 & $-0,41$ & 0,92 \\
\hline Ho & $-0,89$ & 0,87 & 0,95 & 0,04 & 0,46 & 0,58 & 0,59 & $-0,33$ & 0,9 \\
\hline Gd & $-0,84$ & 0,83 & 0,89 & $-0,14$ & 0,61 & 0,48 & 0,5 & $-0,22$ & 0,97 \\
\hline Dy & $-0,87$ & 0,85 & 0,93 & $-0,02$ & 0,54 & 0,54 & 0.57 & $-0,27$ & 0,92 \\
\hline Eu & $.0,75$ & 0,72 & 0,81 & $-(0,25$ & 0,76 & 0,42 & 0,44 & 0 & 0,93 \\
\hline $\mathrm{Sm}$ & $-0,89$ & 0,87 & 0,95 & 0,05 & 0,45 & 0,59 & 0.59 & $-0,34$ & 0,89 \\
\hline Nd & $-0,92$ & 0,9 & 0,97 & 0,11 & 0,42 & 0,54 & 0,65 & $-0,37$ & 0,89 \\
\hline $\mathrm{Ce}$ & $-0,94$ & 0,91 & 0,98 & 0,13 & 0,46 & 0,48 & 0,69 & $-0,33$ & 0,89 \\
\hline La & 0,95 & 0,89 & 0,98 & 0,24 & 0,46 & 0,38 & 0,78 & 0,26 & 0,83 \\
\hline $\mathrm{TuO}_{2}$ & $-0,81$ & 0,84 & 0,82 & $-0,19$ & 0,61 & 0,34 & 0,44 & $-0,25$ & \\
\hline $\mathrm{MnO}$ & 0,47 & $-0,59$ & $-0,46$ & $-(0,49$ & 0,61 & $-(0,39$ & $-0,32$ & & \\
\hline $\mathrm{SiO}_{2}$ & $-0,86$ & 0,78 & 0,81 & 0.74 & 0,1 & $-0,08$ & & & \\
\hline $\mathrm{P}_{2} \mathrm{O}_{5}$ & $-0,25$ & 0,28 & 0,4 & $-(1), 2$ & $-0,04$ & & & & \\
\hline $\mathrm{FeO}$ & $-0,27$ & 0.2 & 0,3 & $-0,56$ & & & & & \\
\hline $\mathrm{Fe}_{2} \mathrm{O}_{3}$ & $-0,42$ & 0,36 & 0,34 & & & & & & \\
\hline $\mathrm{Al}_{2} \mathrm{O}_{3}$ & $-0,98$ & 0.96 & & & & & & & \\
\hline $\mathrm{MgO}$ & $-0,98$ & & & & & & & & \\
\hline
\end{tabular}

titos e os dolomitos encaixantes é produto de metassomatismo magnesiano sobre rochas dolomíticas. Considera ainda que as anomalias negativas de $\mathrm{Ce}$ e Eu são associadas, respectivamente, a um ambiente marinho e a um ambiente redutor. Já a anomalia positiva de Eu encontrada em alguns depósitos de magnesita é explicada por este autor como um testemunho de depósito metassomático em que os
Tabela 3- Matriz de correlação dos mármores dolomíticos

\begin{tabular}{|c|c|c|c|c|c|c|c|c|c|}
\hline & $\mathrm{CaO}$ & $\mathrm{MgO}$ & $\mathrm{Al}_{2} \mathrm{O}_{3}$ & $\mathrm{Fe}_{2} \mathrm{O}_{3}$ & $\mathrm{FeO}$ & $\mathrm{SiO}_{3}$ & MnO & $\mathrm{TiO}_{2}$ & $\mathrm{P}_{2} \mathrm{O}_{5}$ \\
\hline Lu & 0,07 & $-0,17$ & 0,68 & 0,73 & 0,54 & 0.2 & 0,3 & 0,98 & 1 \\
\hline $\mathrm{Yb}$ & 0,08 & $-0,18$ & 0,68 & 0,73 & 0,55 & 0,19 & 0,3 & 0,98 & 1 \\
\hline $\bar{E} \mathbf{r}$ & 0,1 & $-0,2$ & 0,66 & 0,73 & 0,53 & 0,18 & 0,32 & 0,98 & 1 \\
\hline $\mathrm{Ho}$ & 0,1 & $.0,19$ & 0,66 & 0,72 & 0,54 & 0,17 & 0,32 & 0,98 & 1 \\
\hline Gd & 0,13 & $-0,23$ & 0,67 & 0,73 & 0,54 & 0,17 & 0.35 & 0,98 & 0,99 \\
\hline$\overline{\mathrm{Dy}}$ & 0,11 & $-0,2$ & 0,66 & 0.73 & 0.54 & 0.17 & 0,33 & 0,98 & 1 \\
\hline Eu & 0,17 & $.0,26$ & 0,63 & 0,73 & 0,55 & 0,13 & 0,38 & 0,97 & 0,99 \\
\hline $\mathrm{sm}$ & 0,15 & $-0,25$ & 0,67 & 0,76 & 0,54 & 0,18 & 0.37 & 0,97 & 0,99 \\
\hline Nd & 0,22 & $-0,32$ & 0,66 & 0,78 & 0,53 & 0,16 & 0,43 & 0,96 & $0,9 \overline{8}$ \\
\hline $\mathrm{Ce}$ & 0,28 & $-0,38$ & 0,6 & 0,78 & 0,59 & 0,13 & 0,51 & 0,94 & 0,97 \\
\hline La & 0,5 & $-0,6$ & 0,45 & 0,75 & 0,68 & 0,06 & 0,74 & 0,79 & $0,8,3$ \\
\hline $\mathrm{P}_{2} \mathrm{O}_{5}$ & 0,07 & $.0,17$ & 0,66 & 0,74 & 0,53 & 0,19 & 0,29 & 0,97 & \\
\hline $\mathrm{TiO}_{2}$ & $-0,02$ & $-0,09$ & 0,78 & 0,71 & 0.56 & 0.26 & 0,22 & & \\
\hline $\mathrm{MnO}$ & 0,93 & $.0,97$ & $=0,12$ & 0,4 & 0,44 & $-0,24$ & & & \\
\hline$\overline{\mathrm{SiO}}_{z}$ & $-0,48$ & 0.31 & 0,62 & 0,58 & 0,16 & & & & \\
\hline $\mathrm{FCO}$ & 0,16 & $-0,22$ & 0,49 & 0,42 & & & & & \\
\hline $\mathrm{Fe}_{2} \mathrm{O}_{3}$ & 0.13 & $-0,29$ & 0,67 & & & & & & \\
\hline $\mathrm{Al}_{2} \mathrm{O}_{3}$ & $-0,39$ & 0,26 & & & & & & & \\
\hline$\overline{\mathrm{MgO}}$ & $-0,98$ & & & & & & & & \\
\hline
\end{tabular}

fluidos metassomatizantes foram envolvidos na decomposição de feldspatos antes da formação das magnesitas, uma vez que os feldspatos, para estes autores, são os únicos minerais formadores de rochas magmáticas com excesso de $\mathrm{Eu}$.

No presente caso, a ausência de uma anomalia negativa em Ce e a anomalia negativa de Eu pode indicar que a sequência carbonática 

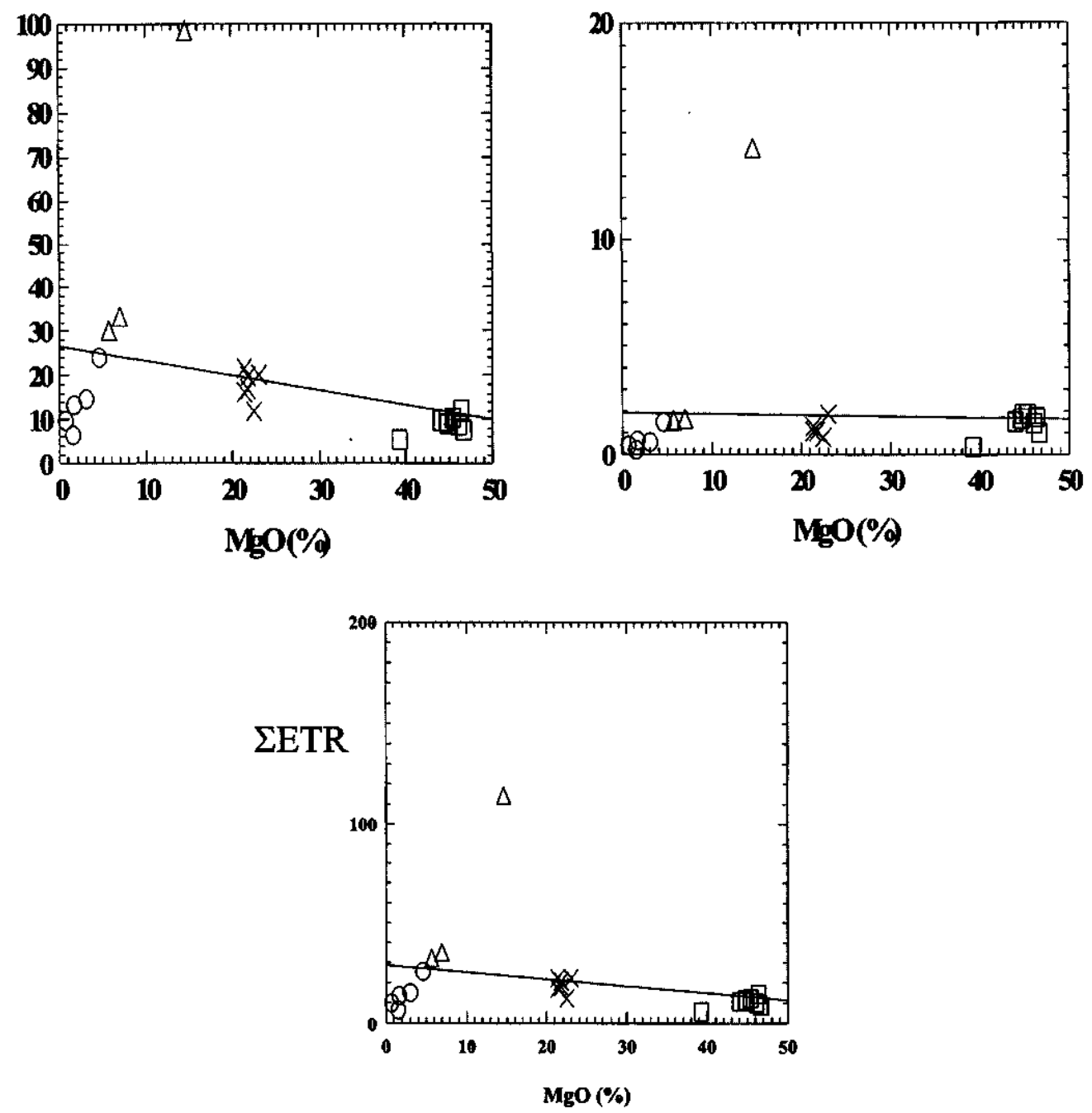

Figura 6 - (a) - Diagramas ETRL vs MgO, (b) - ETRP vs MgO e (c) -ETR vs MgO das rochas metacarbonaticas estudadas. Simbolos são como na figura $5 d$.

Tabela 4- Matriz de correlação dos mármores magnesíticos

\begin{tabular}{|c|c|c|c|c|c|c|c|c|c|}
\hline & $\mathrm{CaO}$ & $\mathrm{MgO}$ & $\mathrm{Al}_{2} \mathrm{O}_{3}$ & $\mathrm{Fe}_{2} \mathrm{O}_{3}$ & $\mathrm{FeO}$ & $\mathrm{SiO}_{2}$ & $\mathrm{MnO}$ & $\mathrm{P}_{2} \mathrm{O}_{3}$ & $\mathrm{TiO}_{2}$ \\
\hline Lu & $-0,81$ & 0,75 & 0,16 & $-0,31$ & $-(1,08$ & 0,22 & $-0,7$ & i) & 0,17 \\
\hline $\mathrm{Yb}$ & $-0,76$ & 0,66 & 0,31 & $-0,29$ & $-0,12$ & 0,39 & $-0,78$ & 0 & 0,28 \\
\hline$E r$ & $.0,8$ & 0,74 & 0,12 & $-0,28$ & $-0,21$ & 0,23 & $-0,8$ & 0 & 0,69 \\
\hline $\mathrm{Ho}_{0}$ & $-0,77$ & 0,75 & 0 & $\frac{0.29}{-0.29}$ & $\frac{-1,2}{-0,2}$ & 0,12 & $-0,77$ & 0 & $-0,03$ \\
\hline$\overline{D y}$ & $-0,63$ & 0,6 & 0,05 & $-0,42$ & 0 & 0,2 & $-0,82$ & 0 & $-0,01$ \\
\hline $\mathrm{Gd}$ & $-0,73$ & 0.71 & 0,04 & $.0,33$ & $-(0,14$ & 0,15 & $-0,8$ & 7 & 0,02 \\
\hline Eu & $-0,61$ & 0,66 & $-0,22$ & $-0,45$ & $-(0,04$ & $-0,06$ & $-0,8$ & 0 & $-0,25$ \\
\hline $\mathrm{sm}$ & $-0,65$ & 0,63 & 0,06 & $-0,28$ & $-0,22$ & 0,18 & $-0,8$ & 0 & (1),03. \\
\hline Nd & $-0,73$ & 0,68 & 0,14 & $-0,22$ & $-0,33$ & 0,2 & $-0,8$ & $\theta$ & 0,15 \\
\hline $\mathrm{Ce}$ & $-0,68$ & 0,66 & 0,08 & $-0,16$ & 40,34 & 0,09 & $-0,69$ & 0 & 0,13 \\
\hline$\frac{L}{L a}$ & $-0,46$ & 0,5 & $-0,11$ & $\frac{-0,010}{-(1,21}$ & $\frac{-0,28}{-0,28}$ & $-0,09$ & $-0,63$ & 0 & $-0,04$ \\
\hline $\mathrm{TTO}_{2}$ & $-0,15$ & $-0,11$ & 0,97 & $-0,03$ & 0,17 & 0,88 & $\frac{0,0,14}{-0,14}$ & 0 & \\
\hline $\mathrm{P}_{2} \mathrm{O}_{5}$ & 0 & 0 & 0 & (1) & 0 & (1) & (1) & & \\
\hline $\mathrm{MnO}$ & 0,73 & $-0,69$ & $.0,1$ & 0,7 & $-(0,09)$ & $-0,28$ & & & \\
\hline $\mathrm{SiO}_{2}$ & $-0,08$ & $-(0,18$ & 0,95 & $-0,08$ & 0,18 & & & & \\
\hline $\mathrm{FeO}$ & 0,17 & $-0,2$ & 0,13 & -0.7 & & & & & \\
\hline $\mathrm{Fe}_{2} \mathrm{O}_{3}$ & 0,39 & $-0,42$ & 0,07 & & & & & & \\
\hline $\mathrm{Al}_{2} \mathrm{O}_{3}$ & $-0,06$ & $-(0,22$ & & & & & & & \\
\hline MgO & $-0,96$ & & & & & & & & \\
\hline
\end{tabular}

magnesiana estudada desenvolveu-se em ambiente marinho parálico de profundidades variáveis, mas plataformal raso, com influência euxínica. A presença de metapelitos intercalados juntos aos metadolomitos de Alencar, a ocorrência de brechas de dissolução, as associações de minerais de ambiente evaporítico, encontradas por Parente (1995) e Parente et al. (1996), e as inclusões de petróleo nas magnesitas, recém descobertas por um colega da UNISINOS Prof. Luís Henrique Ronchi (informação verbal) são argumentos complementares. Além disso, pode-se pensar também que os ETR não estavam distribuídos em água do mar equilibrada com nódulos de $\mathrm{Mn}$,

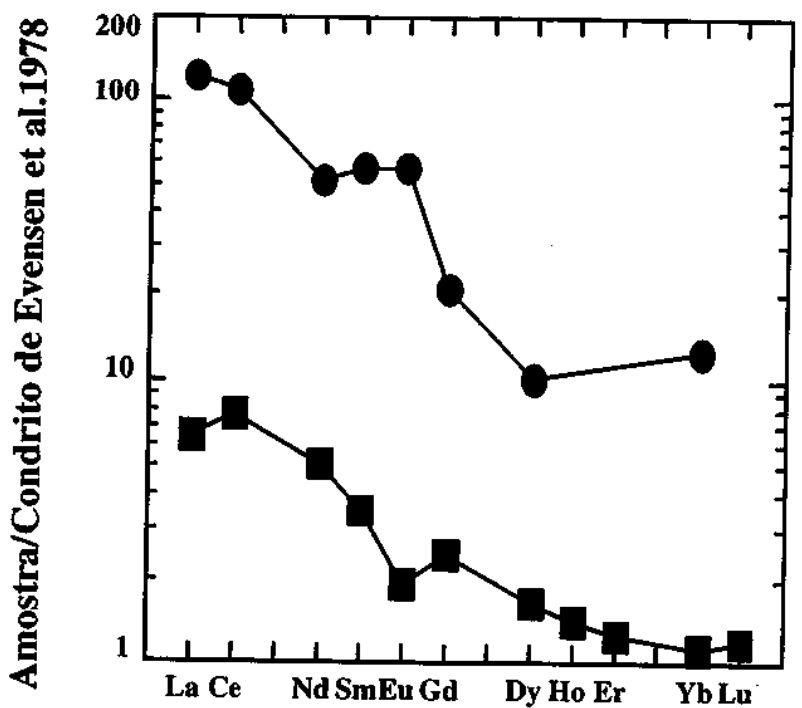

Figura 7 - Padrão mostrando a média dos magnesititos espáticos da Província Liadong e do depósito de Cabeça de Negro normalizado ao condrito de Evensen et al. (1978). Dados de Quisheng (1988). A curva com os quadrados corresponde à média de 8 amostras do Depósito de Cabeça de Negro e a com círculos a média 11 amostras da Província Liadong. 
ou em outras palavras, não existiam nódulos de Mn na época da deposição da sequência carbonática magnesiana estudada.

A anomalia negativa do Eu pode indicar também que a sequência metacarbonática estudada desenvolveu-se em períodos Pós-Arqueano, mais precisamente no Proterozóico, dentro de um ambiente marinho parálico.

Por outro lado, ao comparar, através dos ETR (Fig. 7), os mármores magnesíticos espáticos estudados com os mármores magnesíticos espáticos de Liaodong-China, de idade paleoproterozóica, que apresentam os mesmos aspectos petrográficos e texturais, verifica-se um padrão de distribuição dos ETR mais ou menos similar. Entretanto, algumas diferenças são notáveis, entre as quais vale assinalar: os mármores magnesíticos da Província Liadong são muito mais enriquecidos em ETR que os mármores magnesíticos estudadas; eles apresentam em média uma anomalia positiva de $\mathrm{Eu}$, enquanto os mármores magnesíticos estudados apresentam uma anomalia negativa. Vale assinalar que as magnesitas da Província Liadong desenvolveram-se ao final do Arqueano e início do Paleoproterozóico $(\sim 2.5 \mathrm{Ga})$, período em que havia ainda maior influxo de fluidos hidrotermais nos mares primitivos, de modo que o maior enriquecimento dos ETR assim como a anomalia positiva do Eu podem estar associados a esse período de formação. Assim, independentemente de algumas diferenças, o conjunto de caracteres sugere que essas associações se desenvolveram dentro de um ambiente plataformal mais ou menos similar e que a formação das rochas magnesíticas, sobretudo as espáticas pré-cambrianas, é dominantemente de origem sedimentar.
CONCLUSÃO O estudo geoquímico, através dos ETR, da sequência metacarbonática magnesiana da Faixa Oro s mostrou que existe uma nítida diferença entre os mármores calcíticos, dolomíticos e magnesiticos.

Nos mármores calcíticos, os ETR apresentam uma correlação positiva com o $\mathrm{Al}_{2} \mathrm{O}_{3}$, indicando que grande parte desses elementos podem estar associados à fração argilosa presente nos mármores calcíticos, enquanto nos mármores dolomíticos e magnesíticos, os ETR não apresentam correlação com o $\mathrm{Al}_{2} \mathrm{O}_{3}$, ou mesmo com outros elementos, sugerindo que nessas rochas, em particular nos mármores magnesíticos, os ETR possam se distribuir sob forma de compostos orgânicos ou compostos mais solúveis.

Os mármores magnesíticos estudados são caracterizados por uma anomalia positiva de $\mathrm{Ce}$, que pode indicar um ambiente plataformal marinho raso com influência de águas continentais, e uma anomalia negativa de $\mathrm{Eu}$, que sugere um ambiente marinho parálico com condições redutoras. Eles mostram ainda uma anomalia positiva de $\mathrm{Ce}$ e Eu em relação à água do mar atual, o que pode sugerir diferenças composicionais caracterizadas sobretudo por um enriquecimento desses elementos nas águas do mar primitivo.

Agradecimentos Os autores, em particular C.V.P., agradecem à FUNCAP (proc. 110/95) pelo apoio aos trabalhos de campo e às análises de laboratório e aos revisores indicados pela $\mathrm{RBG}$, pela análise crítica e minuciosa do artigo, cujas sugestões foram valiosas para o aperfeiçoamento deste trabalho.

\section{Referências}

Eterhidge, H \& Greaves, M. 1982. The rare earth elements in seawater. Nature 296(18):214-219.

Evensen, N.M.; Hamilton, P.J.; O'Nions, R.K. 1978. Rare-earth abundance in chondritic meteoritos. Geochim. Cosmochim. Acta, 31: 1637-1665.

Fleet, A J. 1984. Aqueous and sedimentary geochemistry of the rare earth elements. In Rare Earth Element Geochemistry Eds. Henderson P and Fyfe, W.S. Elsevier. 343-373.

Haskin, L.A.; Haskin, M.A.; Frey, F.A.; Wildeman, T.R. 1968. Relative and absolute terrestrial abundances of the rare earths. In: L.H. AHRENS (Editor), Origin and Distridution of the elements. Pergamon, Oxford, pp.889-912.

Hogdahl, O. T.; Melson, S.; Bowen, V.T. 1968. Neutron activacion of lanthanide elements in seawater. Adv.Chem.Ser., 73:308-325.

McLennan, S.M.; Freyer, B.J.; Young, G.M. 1979. The geochemistry ofthe carbonate rich Espanhola Formation (huronian) with emphasis on the rare earth elements. Can. J. Earth. Sei. 16: 230-239.

Michard, A.; Albarede, F.; Michard, G.; Monster, J.F.; Charlous, J. L. 1983. Rare-earth elements and uranium in high-temperature solutions from East Pacific Rise hydrotermal vent field $\left(13^{\circ} \mathrm{N}\right)$. Nature, $\mathbf{3 0 3}(30)$ : 795-797.

Möller, P. 1989. Minor and trace elements in magnesite. Monograph Series Mineral Deposits .28:173-195.

Morteani, G.; Möller, P.; Schley, F. 1982. The Rare Earth Element contents and the origin of the sparry magnesite mineralizations of Tux-Lanersbach, Entachen Alm, Spiessnagel, and Hochfilzen, Áustria, and the lacustríne magnesite deposits of Aiani-Kozani, Greece, and Bela Stena, Yugoslavia. Economia Geology, 77:617-631.

Morteani, G.; Schely, F.; Möller, P. 1983. On the formation of magnesite. In: Mineral Deposits of the Alps and of the Alpine Epoch in Europe (ed. H.J. Schneider). Springer-V. Berlin Heidelberg; 105-116.

Parente, C. V. 1995. Géologie et paléogégraphie d'une plate-forme à évaporites et magnesite d'age protérozoique ( $2 \mathrm{Ga}$ ): le cadre géotectonique initial de Ia ceinture mobile Orós dans Ia région d'Alencar (Ceará-Brésil). Thèse de Doctorat de 1'Université de Nantes. $306 \mathrm{p}$ (inédite).
Parente, C. V. \& Arthaud, M. H. 1995. O Sistema Orós-Jaguaribe no Ceará-NE do Brasil. Revista Brasileira de Geociencias, 25(4):297-305

Parente, C.V.P.; Guillou, J.J.; Barbosa, H. S. 1996. Evaporitos pré-cambrianos ( 1.8Ga) da Faixa Orós, Ceará (Brasil). Revista de Geologia, 9:5-16.

Piper, D .Z. 1974. Rare earth elements in ferromanganese nodules and other marine phases. Geochem. Cosmochim. Acta, 38:1007-1022.

Qiuzjemg, Z. 1988. Early Proterozoic tectonic styles and associated mineral deposits ofthe north China Platform. Precambrian Research, 39:1-29.

Ronov, A B.; Blashov, Y.A; Grini, Y. P.; Bratishko, R. K..; Kasakov, G. A. 1974. Regularities of rare earth element distribution in the sedimentary shell and in the crust ofthe earth. Sedimentology, 145:171-193.

Sá, J.M. 1991. Evolution geodynamique de Ia ceinture protérozoique d'Orós, Nord-Est du Brésil. Thèse de doctorat de l'Université de Nancy I, 117p

Tlig, S. 1987. The Sr and rare earth element (REE) behaviour during diagenesis of limestone in various environmental conditions. In the praticai applications of trace elements and isotopes to environmental biogeochemistry and mineral resources evaluation. Eds. Hurst, R.W; Davis, T.E.; Augustithis, S.S. Ed.Theophrastus Publications, S. A .103-147.

Tufar, W.; Gieb, J.; Schmidt, R.S.; Möller, P.; Pohl, W.; Hiedler, H.; Olsacher, A. 1989. Formation of magnesite in the Radenthein (Carinthia/Austria) type locality. Monograph Series Mineral Deposits. 28:135-171.

Van Schmus, W.R.; Brito Neves, B. B.; Hackspacher, P.; Baabinski, M. 1995. U/Pb and $\mathrm{Sm} / \mathrm{Nd}$ geochronologic studies of the eastern Borborema Province, Northeastern Brazil: initial conclusions. J. South American Earth Sciences, 8(3/4):267-288.

Manuscrito A-967 Recebido em 24 de março de 1998 Revisão dos autores em 25 de agosto de 1998 Revisão aceita em 27 de agosto de 1998 